\title{
Surgical Removal of a Giant Sialolith by Diode Laser
}

\author{
Yeliz Kılınç*, Sedat Çetiner \\ Department of Oral and Maxillofacial Surgery, Faculty of Dentistry, Gazi University, Ankara, Turkey \\ Email: dtykilinc@hotmail.com, scetiner@gazi.edu.tr
}

Received 16 August 2014; revised 1 October 2014; accepted 17 October 2014

Copyright (C) 2014 by authors and Scientific Research Publishing Inc.

This work is licensed under the Creative Commons Attribution International License (CC BY).

http://creativecommons.org/licenses/by/4.0/

(c) (i) Open Access

\begin{abstract}
Giant sialoliths larger than $20 \mathrm{~mm}$ are rare. The surgery has to be performed with the minimally invasive method in order to avoid the morbidity associated with the surgical techniques. In this report the surgical removal of a giant sialolith of $25 \mathrm{~mm}$ by using diode laser is described. A 57year-old female was presented with a firm mass in the anterior part of the left side of the floor of the mouth. Following the clinical and radiological examination, the left submandibular duct sialolith was diagnosed. The diode laser was used with a power setting of $810 \mathrm{~nm}$ of wavelength, 4.0 $W$ of power, $0.5 \mathrm{~ms}$ continuous wave and $1000 \mathrm{~Hz}$ of frequency for the incision. The giant sialolith was adequately removed under local anesthesia. The procedure was well-tolerated. The wound healing was uneventful in the postoperative period. By the 10th day after surgery the patient had no complaints and the salivary flow was normal. It was concluded that the use of 810 -nm diode laser application is a safe and useful technique. Due to the excellent cutting and coagulation ability, there is a low complication rate, making it an appropriate alternative for this type of surgical procedure.
\end{abstract}

\section{Keywords}

Salivary Gland Calculi, Salivary Ducts, Submandibular Gland, Lasers

\section{Introduction}

Sialolithiasis is the most common disease of the salivary glands. It is characterized by the development of calcifications (sialoliths) that accumulate within the salivary gland parenchyma and associated ductal systems. Most of the sialoliths are found in the submandibular gland [1]-[3]. They are usually measured less than $10 \mathrm{~mm}$, by

"Corresponding author. 
the contrary to bigger ones, described as megaliths or giant sialoliths in the literature [4] [5].

Sialoliths become symptomatic when their sizes reach to obstruct the duct, causing painful swelling particularly in meal times and even acting as a source of deep neck infection [2] [6]. Therefore removal of the sialolith is of a clinical concern. Various types of lasers have been employed to treat sialolithiasis, including carbon dioxide, diode, Ho:Yag and Nd:YAG lasers [6]-[9].

In this paper the authors aim to present a case of symptomatic giant sialolith of the Wharton Duct removed surgically by using diode laser.

\section{Case Report}

A 57-year-old female patient was referred to Gazi University, Faculty of Dentistry, Department of Oral and Maxillofacial Surgery for the assessment of a firm mass in the anterior part of the left side of the floor of the mouth (Figure 1). Medical history of the patient was unremarkable except that she underwent total thyroidectomy due to the multiple growing nodules. She reported that she had a swelling and pain in the submandibular left region especially during meals. Although she was aware of the lesion for four months, no treatment had been applied.

Extraoral examination revealed a palpable left submandibular gland and intraoral examination noted a large, firm and mild-tender swelling in the left anterior floor of the mouth in the region of the submandibular duct. Panoramic and occlusal radiographs were obtained for radiographical examination. Panoramic radiograph showed a large radioopaque mass superimposed on the left canine and premolar areas. A lower occlusal radiograph showed the large radioopaque mass in the left Wharton Duct (Figure 2, Figure 3)

On the basis of clinical and radiological findings, the left submandibular duct sialolith was diagnosed and the patient was scheduled to surgically remove the sialolith using diode laser. The diode laser was used (Lambda Scientifica srl, Doctor Smile Er \& Diode Laser) with a power setting of $810 \mathrm{~nm}$ of wavelength, $4.0 \mathrm{~W}$ of power, $0.5 \mathrm{~ms}$ continuous wave and $1000 \mathrm{~Hz}$ of frequency was selected. Following induction of local infiltration anesthesia with $2 \mathrm{ml} 4 \%$ articaine with 1/100,000, the sialolith was localized and grasped with two mosquito hemostats. An incision was made directly over the sialolith to expose it (Figure 4). The duct along with the oral mucosa was incised from the ostium until the stone was visible using the diode laser. Following the incision a dissecting scissors was used to dilate the incision wound and expose the sialolith. After the exposure, the sialolith was grasped with the mosquito hemostat and removed from the duct. Once the stone was retrieved, the duct was marsupialised into the floor of the mouth with 5.0 vicryl sutures. The sialolith was ovoid, hard, yellow and 25 mm long (Figure 5).

The patient was prescribed a combined antibiotic regimen (consisting of amoxicillin clavulonate every $12 \mathrm{~h}$ for $5 \mathrm{~d}$ and rovamycine every $12 \mathrm{~h}$ for $5 \mathrm{~d}$ ), a nonsteroidal anti-inflammatory drug (100 mgr flurbiprofen every $12 \mathrm{~h}$ for $3 \mathrm{~d})$ and an oral rinse $(0.2 \%$ chlorhexidine gluconate ,three times daily for $7 \mathrm{~d})$. On the 10th day after intervention the patient had no complaints. No sign of infection was observed and salivary flow was normal.

\section{Discussion}

Sialolithiasis accounts for the majority of the salivary gland dysfunction and is the most common factor of

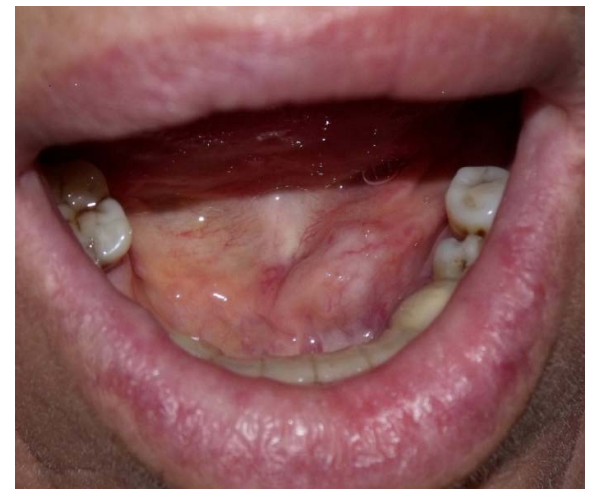

Figure 1. A sialolith which was localized on the left side of the floor of the mouth. 


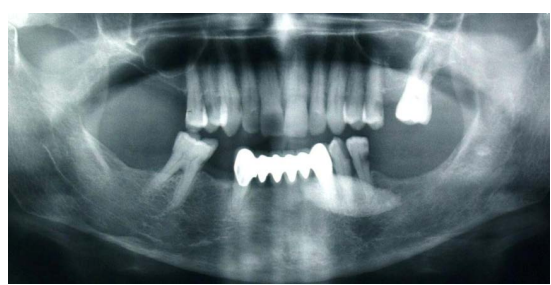

Figure 2. Panoramic radiograph showing the sialolith superimposed oner the canine-premolar area.

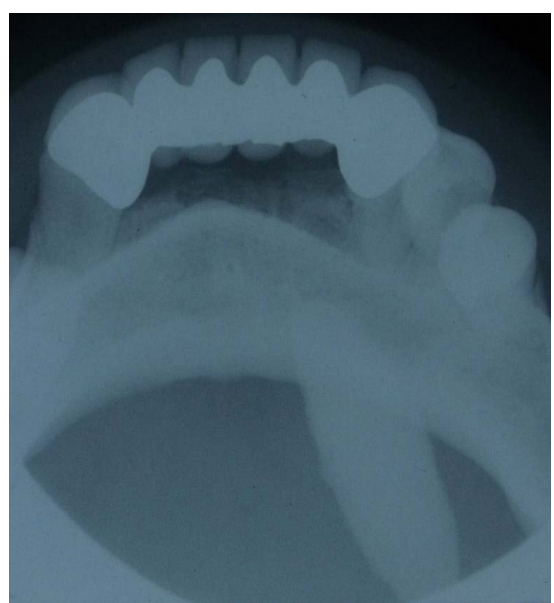

Figure 3. Lower occlusal radiograph showing the sialolith.

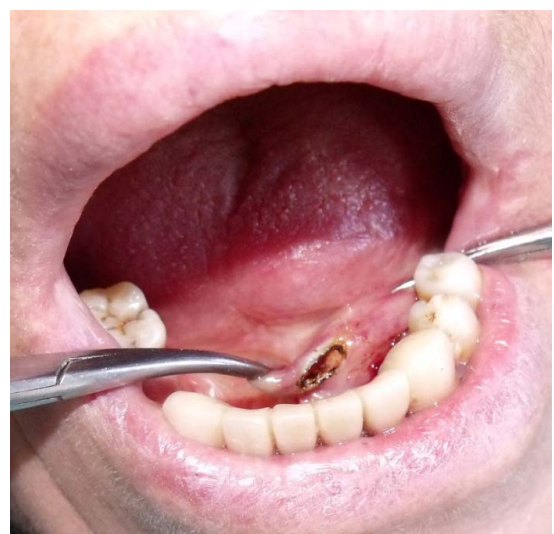

Figure 4. Diode laser was used to incise the mucosa over the sialolith.

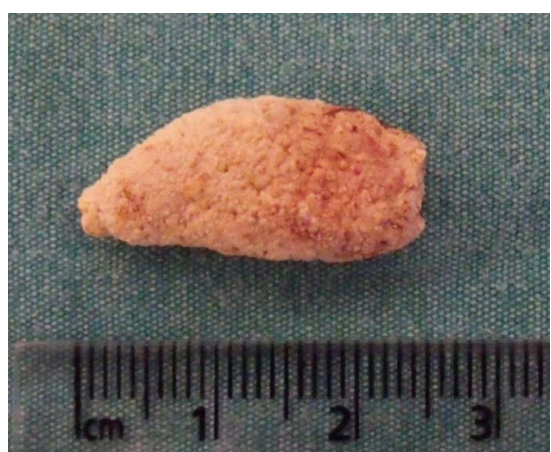

Figure 5. Giant sialolith removed from the Wharton Duct. 
acute and chronic infections [10]. Infection, inflammation of the gland, physical trauma to the duct or its orifice, introduction of foreign bodies or the presence of desquamated epithelial cells are associated with the development of sialoliths [1] [3] [11].

Sialoliths are commonly measured between 5 and $10 \mathrm{~mm}$ in size. Giant sialoliths are defined as those measuring more than $15 \mathrm{~mm}$ in any one dimension and considered rare [11] [12]. The ability of a calculus to grow and become a sialolith is associated mainly with the reaction of the affected duct. The continuous growth of the sialolith leads to the increasing obstruction of the salivary secretion, thereby causing swelling, pain and infection of the gland [11]. If the duct adjacent to the sialolith has enough dilatation, providing a nearly normal salivary secretion, there might be a long asymptomatic period and eventually a giant sialolith will develop [11] [13]. It is considered that a calculus may enlarge at a rate of approximately $1-1.5 \mathrm{~mm}$ per year [5] [14]. In this sense it can be anticipated for the present case that the giant sialolith of $25 \mathrm{~mm}$ began to develop years before.

In this case the giant sialolith of $25 \mathrm{~mm}$ was located in the submandibular gland duct which was reported to be the most susceptible to calculus formation [1]-[4] [11] [15] [16]. There are several factors contributing to the increased incidence of sialoliths in the submandibular gland. These include alkalinity of its saliva, greater concentration of calcium and phosphate and a higher mucus content [1] [3] [4] [15]. Moreover the submandibular duct is longer and has a kink at the rear floor of the mouth, leading to a particular tendency to secretory congestion [3].

The goal of the treatment is the restoration of normal salivary secretion and the treatment options depend upon the location and size of the sialolith. Patients presenting with small sialolithiasis may benefit from conservative approaches including hydration, moist warm heat and gland massage [1]. Generally, it is accepted to remove the distal stones by simple intraoral surgery, whereas intraglandular sialoliths may necessitate sialadenectomy [17] [18]. In the present case the sialolith was removed simply by means of laser surgery.

The rationale for the surgical removal is that the sialolith should be removed with the minimally invasive method by means of transoral sialolithotomy, to avoid the morbidity associated with sialadenectomy [11]. Based on this fact various type of lasers have been used for the treatment of sialolithiasis, including carbon dioxide, diode, Ho:Yag and Nd:YAG lasers [6] [9]. Among these diode laser has been reported to have more advantages. It has a greater absorption by hemoglobin, oxyhemoglobin and melanin, thereby making its penetration depth smaller than neodymium: yttrium-aluminum-garnet (Nd-YAG) laser. Owing to the smaller penetration in blood rich tissues diode laser is accepted to be safe in the adjacent tissues. The diode laser has a greater but still predictable penetration depth compared to $\mathrm{CO}_{2}$ laser [19] [20]. Angiero et al. employed diode laser for treating sialolithiasis of the submandibular gland and concluded that the procedure is safe and carries a low complication risk [7]. As in the present case the healing period was uneventful and no postoperative complications developed. Due to its excellent cutting and coagulation ability diode laser is an alternative option for the soft tissue surgery.

As a consequence sialolithiasis should be considered when submandibular pain is related with the meal times. Minimally invasive techniques should be employed for the surgical interventions. In this paper the diode laser was adequately applied for the surgical removal of giant sialolith and no postoperative complications were encountered. Owing to the excellent features of diode laser, it is a valid tool for the soft tissue surgery of the oral cavity.

\section{References}

[1] Huang, T.C., Dalton, J.B., Monsour, F.N. and Savage N.W. (2009) Multiple, Large Sialoliths of the Submandibular Gland Duct: A Case Report. Australian Dental Journal, 54, 61-65. http://dx.doi.org/10.1111/j.1834-7819.2008.01091.x

[2] Iqbal, A., Gupta, A.K., Natu, S.S. and Gupta, A.K. (2012) Unusually Large Sialolith of Wharton’s Duct. Annals of Maxillofacial Surgery, 2, 70-73. http://dx.doi.org/10.4103/2231-0746.95327

[3] Leung, A.K., Choi, M.C. and Wagner, G.A. (1999) Multiple Sialoliths and a Sialolith of Unusual Size in the Submandibular Duct: A Case Report. Oral Surgery, Oral Medicine, Oral Pathology, Oral Radiology, and Endodontology, 87, 331-333. http://dx.doi.org/10.1016/S1079-2104(99)70218-0

[4] Ledesma-Montes, C., Garcés-Ortíz, M., Salcido-García, J.F., Hernández-Flores, F. and Hernández-Guerrero, J.C. (2007) Giant Sialolith: A Case Report and Review of the Literature. International Journal of Oral and Maxillofacial Surgery, 65, 128-130. http://dx.doi.org/10.1016/j.joms.2005.10.053

[5] Sutay, S., Erdag, T.K., Ikiz, A.O. and Guneri, E.A. (2003) Large Submandibular Gland Calculus with Perforation of the Floor of the Mouth. Otolaryngology_Head and Neck Surgery, 128, 587-588.

http://dx.doi.org/10.1016/S0194-5998(02)23280-5 
[6] Yang, S.W. and Chen, T.A. (2011) Transoral Carbon Dioxide Laser Sialolithectomy with Topical Anaesthesia. A Simple, Effective, and Minimally Invasive Method. International Journal of Oral and Maxillofacial Surgery, 40, 169-172. http://dx.doi.org/10.1016/j.ijom.2010.09.020

[7] Angiero, F., Benedicenti, S., Romanos, G.E. and Crippa, R. (2008) Sialolithiasis of the Submandibular Salivary Gland Treated with the 810- to 830-nm Diode Laser. Photomedicine and Laser Surgery, 26, 517-521. http://dx.doi.org/10.1089/pho.2007.2226

[8] Martellucci, S., Pagliuca, G., de Vincentiis, M., Greco, A., Fusconi, M., De Virgilio, A., Gallipoli, C. and Gallo, A. (2013) Ho:YAG Laser for Sialolithiasis of Wharton's Duct. Otolaryngology_Head and Neck Surgery, 148, 770-774. http://dx.doi.org/10.1177/0194599813479914

[9] Jayasree, R.S., Gupta, A.K., Vivek, V. and Nayar, V.U. (2008) Spectroscopic and Thermal Analysis of a Submandibular sialolith of Wharton's Duct Resected Using Nd:YAG Laser. Lasers in Medical Science, 23, 125-131. http://dx.doi.org/10.1007/s10103-007-0458-6

[10] Zenk, J., Benzel, W. and Iro, H. (1994) New Modalities in the Management of Human Sialolithiasis. Minimally Invasive Therapy, 3, 275-284. http://dx.doi.org/10.3109/13645709409153022

[11] Bodner, L. (2002) Giant Salivary Gland Calculi: Diagnostic Imaging and Surgical Management. Oral Surgery, Oral Medicine, Oral Pathology, Oral Radiology and Endodontology, 94, 320-323. http://dx.doi.org/10.1067/moe.2002.123863

[12] Gupta, A., Rattan, D. and Gupta, R. (2013) Giant Sialoliths of Submandibular Gland Duct: Report of Two Cases with Unusual Shape. Contemporary Clinical Dentistry, 4, 78-80. http://dx.doi.org/10.4103/0976-237X.111599

[13] Rai, M. and Burman, R. (2009) Giant Submandibular Sialolith of Remarkable Size in the Comma Area of Wharton's Duct: A Case Report. Journal of Oral and Maxillofacial Surgery, 67, 1329-1332. http://dx.doi.org/10.1016/j.joms.2008.11.014

[14] Alkurt, M.T. and Peker, I. (2009) Unusually Large Submandibular Sialoliths: Report of Two Cases. European Journal of Dentistry, 3, 135-139.

[15] Williams, M.F. (1999) Sialolithiasis. Otolaryngologic Clinics of North America, 32, 819-834. http://dx.doi.org/10.1016/S0030-6665(05)70175-4

[16] Graziani, F., Vano, M., Cei, S., Tartaro, G. and Mario, G. (2006) Unusual Asymptomatic Giant Sialolith of the Submandibular Gland: A Clinical Report. Journal of Craniofacial Surgery, 17, 549-552. http://dx.doi.org/10.1097/00001665-200605000-00027

[17] Combes, J., Karavidas, K. and McGurk, M. (2009) Intraoral Removal of Proximal Submandibular Stones-An Alternative to Sialadenectomy? International Journal of Oral and Maxillofacial Surgery, 38, 813-816. http://dx.doi.org/10.1016/j.ijom.2009.02.026

[18] Zenk, J., Constantinidis, J., Al-Kadah, B. and Iro, H. (2001) Transoral Removal of Submandibular Stones. JAMA Otolaryngology—Head \& Neck Surgery, 127, 432-436. http://dx.doi.org/10.1001/archotol.127.4.432

[19] Ergun, S., Mete, O., Yeşil, S. and Tanyeri, H. (2009) Solitary Angiokeratoma of the Tongue Treated with Diode Laser. Lasers in Medical Science, 24, 123-125. http://dx.doi.org/10.1007/s10103-007-0525-Z

[20] Saleh, H.M. and Saafan, A.M. (2007) Excision Biopsy of Tongue Lesions by Diode Laser. Photomedicine and Laser Surgery, 25, 45-49. http://dx.doi.org/10.1089/pho.2006.2014 
Scientific Research Publishing (SCIRP) is one of the largest Open Access journal publishers. It is currently publishing more than 200 open access, online, peer-reviewed journals covering a wide range of academic disciplines. SCIRP serves the worldwide academic communities and contributes to the progress and application of science with its publication.

Other selected journals from SCIRP are listed as below. Submit your manuscript to us via either submit@scirp.org or Online Submission Portal.
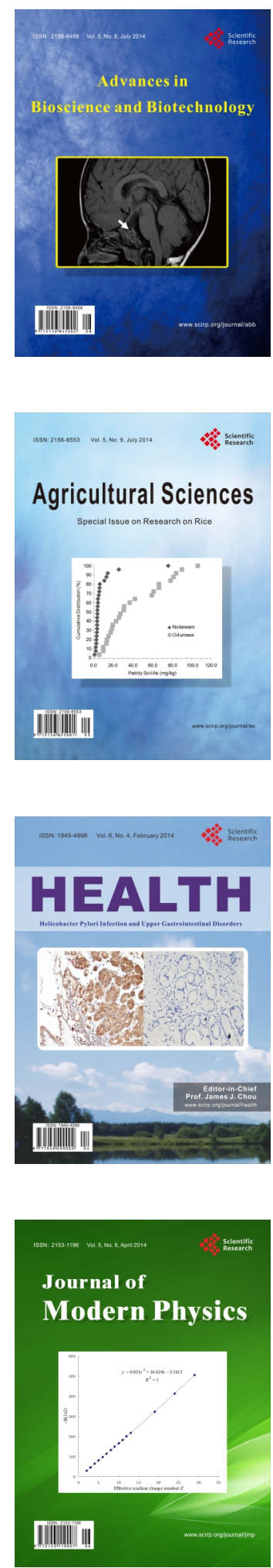
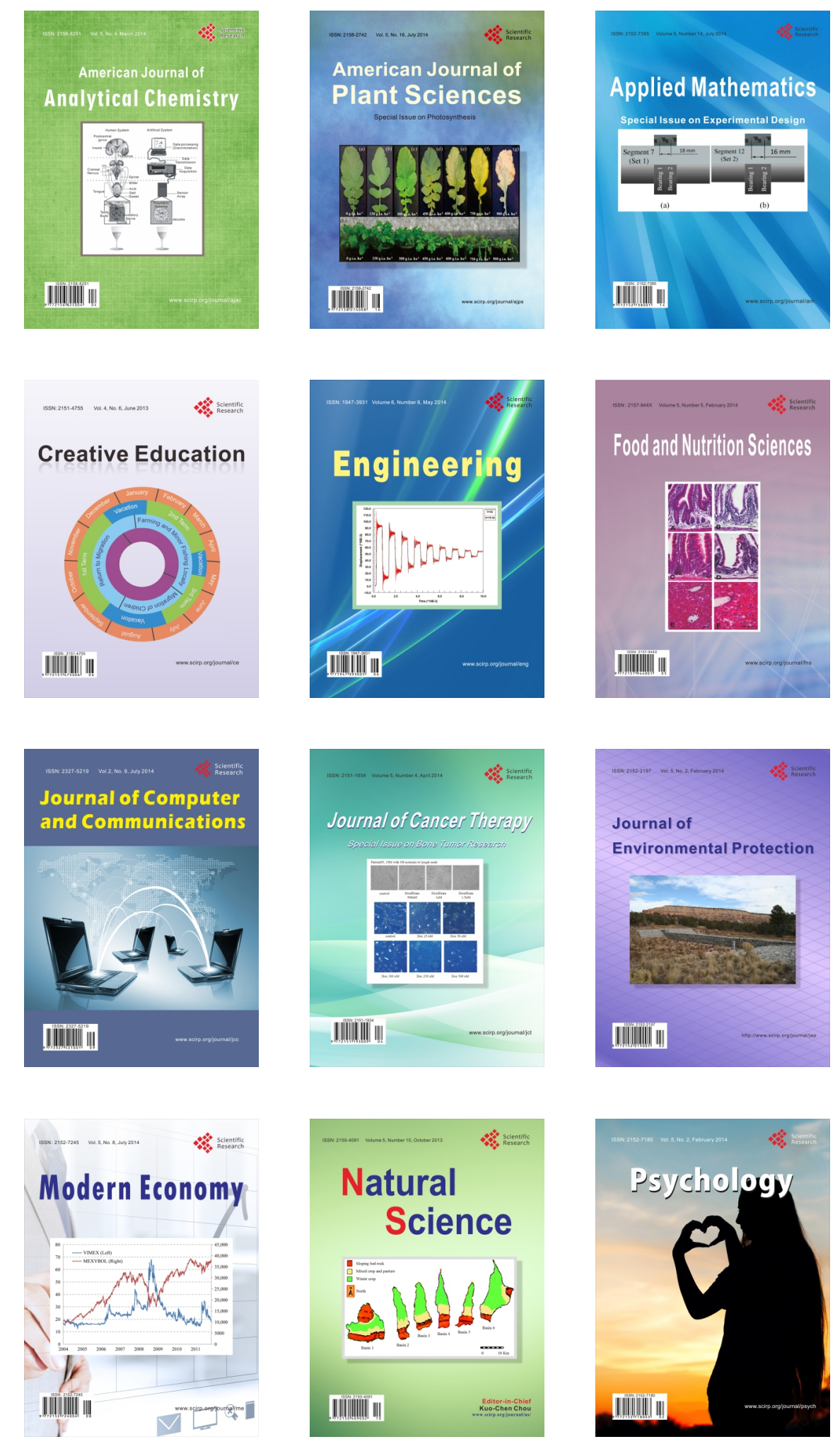